\title{
Pharmacologically mechanistic basis for the traditional uses of Rumex acetosa in gut motility disorders and emesis
}

\author{
Musaddique Hussain ${ }^{1,2}$, Shahid Masood Raza² and Khalid Hussain Janbaz ${ }^{1}$ \\ ${ }^{1}$ Faculty of Pharmacy, Bahauddin Zakariya University, Multan, Pakistan; ${ }^{2}$ School of Pharmacy, The University of \\ Faisalabad, Faisalabad, Pakistan.
}

\begin{tabular}{|c|c|}
\hline \multicolumn{2}{|l|}{ Article Info } \\
\hline Received: & 17 May 2015 \\
\hline Accepted: & 17 June 2015 \\
\hline Available Online: & 1 July 2015 \\
\hline \multicolumn{2}{|c|}{ DOI: 10.3329/bjp.v10i3.23406 } \\
\hline \multicolumn{2}{|c|}{$\begin{array}{l}\text { Cite this article: } \\
\text { Hussain M, Raza SM, Janbaz KH. } \\
\text { Pharmacologically mechanistic basis } \\
\text { for the traditional uses of Rumex ace- } \\
\text { tosa (Linn) in gut motility disorders } \\
\text { and emesis.. Bangladesh J Pharmacol. } \\
\text { 2015; 10:548-54. }\end{array}$} \\
\hline
\end{tabular}

\begin{abstract}
In vitro and in vivo studies were undertaken to evaluate the pharmacologically mechanistic background to validate the traditional uses of Rumex acetosa in the treatment of emesis and gastrointestinal motility disorders such as constipation and diarrhea. In rabbit jejunum preparation, methanolic extract of $R$. acetosa $(0.01-1.0 \mathrm{mg} / \mathrm{mL})$ caused a transient spasmogenic effect, followed by the spasmolytic effect $(3-10 \mathrm{mg} / \mathrm{mL})$. In presence of atropine, spasmogenic effect was blocked while spasmolytic effect was emerged, suggesting that spasmogenic effect was mediated through activation of muscarinic receptors. Extract inhibited the $\mathrm{K}^{+}(80 \mathrm{mM})$-induced contraction, suggesting $\mathrm{Ca}^{2+}$-channel blockade, which was further confirmed when pretreatment of tissue with extract shifted the $\mathrm{Ca}^{2+}$ concentration-response curves to the right, similarly as verapamil. $R$. acetosa also exhibited the significant antiemetic activity $(p<0.05)$ against different emetogenic stimuli, when compared with chlorpromazine. This study confirms the presence of gut modulator (spasmogenic and spasmolytic) and antiemetic activates, validating its traditional uses.
\end{abstract}

\section{Introduction}

Rumex acetosa Linn. (Polygonaceae) is a perennial herb; known by vernacular names of garden sorrel (English), chuukaa (Ayurvedic) and churkuy (Local) and is widely distributed in Asia and Western Himalayas from Kashmir to Kumaon (Khare, 2007).

Phytochemical investigations of aerial parts revealed the presence of ascorbic acid, oxalic acid and flavones such as rutin, vitexin, kaempferol, oxymethylanthraquinone, flavones C-glycosides and flavones $\mathrm{O}$ glycosides (Kato and Morita, 1990), whereas hyperin, chrysophanein, proanthocyanidin and phloroglucinol derivates with anthraquinones, such as chrysophanol, physcion and emodin anthrones were isolated from the roots (Bicker et al., 2009; Lim et al., 2011).

$R$. acetosa has been reported to have diaphoretic, insecticidal, diuretic, antimicrobial, anticancer, anti- septic and antipyretic activities (Lee et al., 2005; Gescher et al., 2011; Wegiera et al., 2011). Decoction of the plant has been used as a folkloric medicine to treat constipation, bronchitis, scurvy, arthritis, gastric ulcer, cramp, diarrhea, sore throat and water retention while seeds are used as astringent in hemorrhages (Kirtikar and Basu, 1984; Duke et al., 2002). Plant has been evaluated pharmacologically for the presence of anticancer (Leonard et al., 2006), anti-ulcerogenic and antiinflammatory activities (Bae et al., 2012).

Although $R$. acetosa has traditionally been used to treat emesis and gastrointestinal ailments, while scientific investigation to validate such traditional uses are so far lacking. The purpose of present study was to investigate its therapeutic potential and possible mechanism of action which may explains the folkloric uses of the plant in emesis and gastrointestinal motility disorders such as constipation and diarrhea. 


\section{Materials and Methods}

Plant collection and extraction: Whole plant of $R$. acetosa was collected from northern areas of Pakistan and was identified by the Curator, Institute of Pure and Applied Biology, Bahauddin Zakariya University, Multan. Electrically grinded coarse powdered material (\#40) was subjected to triple maceration (Hussain et al., 2013), with $70 \%$ methanol-aqueous mixtures to produce the methanolic extract of R. acetosa; named Ra.ME.

Animals: Animals including, chicks (80-95 g, 10-12 days old) Swiss albino mice (35-45 g, 3-4 weeks old,) and rabbits (1.0-1.5 kg, 7-10 months old) of either sex were locally purchased and placed under controlled environmental condition $\left(25-28^{\circ} \mathrm{C}\right)$. Chicks were housed in plastic cages with sawdust as bedding under room temperature with 12 hours/12 hours dark-light cycle, whereas animal were provided with standard diet and ad libitum with tap water. Before the commencement of experiments, food was withdrawn from all animals but had free access to water. All experiments were performed by following ruling of Institute of Laboratory Animal Resources, Commission on Life Sciences (National Research Council, 1996); with reference number EC/06/2012.

Standard drugs and chemicals: Research grade and highest purity chemicals, solvents, and drugs were used in the experimental study. Carbachol, acetylcholine chloride, potassium chloride, magnesium chloride, ethylenediamine tetraacetic acid, and verapamil were purchased from Sigma Chemicals Co. St Louis, MO, USA, whereas dimethysulfoxide, glucose, magnesium sulphate, calcium chloride, sodium bicarbonate, potassium dihydrogen phosphate, tween-80, sodium dihydrogen phosphate, and methanol were obtained from Merck, Darmstadt, Germany. Ammonium hydroxide, sodium chloride, and sodium hydroxide were purchased from BDH Laboratory supplies, Poole, England. Antiemetic drug (chlorpromazine) and emetogenic stimuli (copper sulphate and cisplatin) were obtained from Highnoon pharmaceutical (Pvt.) Ltd. Lahore, Pakistan and Sharlab S. L, Barcelona, Spain, respectively.

Phytochemical screening: Methanolic extract was subjectted to phytochemical screening for the detection of alkaloids, carbohydrates, tannins, saponins, anthraquinones, steroids and flavonoids as possible important constituents of the plant, according to standard method (Evans, 2006).

Acute toxicity test: For the acute toxicity testing, mice were fasted 24 hours prior to test but had free access to water. Twenty mice were divided into four groups (each 5). Group 1 (negative control) was given normal saline $(0.9 \% \mathrm{NaCl} ; 10 \mathrm{~mL} / \mathrm{kg})$ orally whereas group 2, 3 , and 4 (test groups) were orally administered with 2 , 4 , and $6 \mathrm{~g} / \mathrm{kg}$ of methanolic extract of plant, respectively. All 4 groups were kept under regular observation for possible mortality and toxic effects as diarrhea, anorexia, gastrointestinal spasms and behavioral changes for 24 hours.

In vitro assessment of spasmogenic and spasmolytic activity: For the assessment of the possible presence of spasmogenic and spasmolytic activity, methanolic extract was tested on isolated rabbit jejunum preparations, as described previously (Arshad et al., 2012; Hussain et al., 2014). A preload of $1 \mathrm{~g}$ was applied to mesenteries free isolated rabbit jejunum segments $(2-3 \mathrm{~cm})$, suspended in isolated tissue baths containing $10 \mathrm{~mL}$ of Tyrode's solution $\left(\mathrm{KCl} 2.68, \mathrm{NaCl} 136.9, \mathrm{MgCl}_{2} 1.05, \mathrm{NaHCO}_{3}\right.$ 11.90, $\mathrm{NaH}_{2} \mathrm{PO}_{4} 0.42, \mathrm{CaCl}_{2} 1.8$, and glucose $5.55 \mathrm{mM}$ ), aerated with carbogen $\left(37^{\circ} \mathrm{C}\right)$ and tissues response were recorded via displacement transducers (model FT-03) coupled with an oscillograph and powerlab data acquisition system (AD Instruments, Sydney, Australia) linked to a computer installed with labchart software (version 6) (Janbaz et al., 2012; Janbaz et al., 2014). Each tissue was allowed to equilibrate for at least $30 \mathrm{~min}$, with double change of Tyrode's solution. Methanolic extract was applied to tissue bath containing isolated rabbit jejunum preparations in a cumulative fashion, without prior addition of any agonist (Gilani et al., 1994). Contractile effect of the methanolic extract was assessed as the percent of the maximum effect produced by the control drug, acetylcholine $(1.0 \mu \mathrm{M})$.

Confirmation of $\mathrm{Ca}^{2+}$ channel blocking activity: To assess whether the spasmolytic activity of the methanolic extract was through calcium channel blockade (CCB), the tissue preparations were depolarized by exposing to high concentration of $\mathrm{KCl}$, i.e. $\mathrm{K}^{+}(80 \mathrm{mM})$, resulting in appearance of sustained contraction (Farre et al., 1991). Methanolic extract was applied to $\mathrm{K}^{+}(80 \mathrm{mM})$-induced contraction in a cumulative manner, to achieve concentration-dependent inhibitory response. The $\mathrm{K}^{+}(80 \mathrm{mM})$ induced smooth muscle contraction has been reported to be mediated through influx of $\mathrm{Ca}^{2+}$ from extracellular fluid, and the substances capable to inhibit such contractions are speculated to be acting through the blockade of $\mathrm{Ca}^{2+}$ channels (Bolton, 1979).

For confirmation of calcium channel blocking activity of the methanolic extract, the isolated rabbit jejunum preparations were allowed to stabilize in normal Tyrode's solution, and then allowed to subsequently contract on exposure to $\mathrm{K}^{+}(80 \mathrm{mM})$ - which were subsequently replaced with $\mathrm{Ca}^{2+}$-free Tyrode's solution containing EDTA $(0.1 \mathrm{mM})$ for $30 \mathrm{~min}$ to ensure the removal of calcium from the tissues (Janbaz et al., 2013). After $30 \mathrm{~min}$, tissues were further exposed to EDTA containing Tyrode's solution which was $\mathrm{K}^{+}$-rich and $\mathrm{Ca}^{+2}$-free, having the following chemical composition (g/L): $\mathrm{KCl}$ (3.72), $\mathrm{NaCl}$ (5.72), $\mathrm{MgCl}_{2}(0.1), \mathrm{NaHCO}_{3}$ (1.0), $\mathrm{NaH}_{2} \mathrm{PO}_{4}$ (0.05), glucose (1.0), and EDTA (0.37). Subsequent to an incubation period of $40 \mathrm{~min}$, 
cumulative $\mathrm{Ca}^{2+}$ concentrations were applied to the tissue bath to obtain control calcium concentrationresponse curves (CRCs). When control CRCs of $\mathrm{Ca}^{2+}$ were found superimposed, the tissue was pretreated with methanolic extract for $50 \mathrm{~min}$. The $\mathrm{Ca}^{2+}$ channel blocking activity was further confirmed when methanolic extract caused shifting of the CRCs in calcium-free medium towards right in a concentration-dependant manner (Gilani et al., 2005).

In vivo assessment of antiemetic potential: Chick emetic model was slightly modified to assess the antiemetic potential of the methanolic extract (Florczyk et al., 1982; Akita et al., 1998; Eda et al., 2005; Hussain et al., 2015b). Chicks were divided in 4 groups of 5 chicks each. Each chick was set aside in a large beaker for the $15 \mathrm{~min}$ to acclimatize. Chicks of group 1 (control group) were given an oral dose of normal saline $(0.9 \%)$, while the chicks of group 2 and 3 (experimental groups) were given an oral dose of methanolic extract at the dose range of 50 and $100 \mathrm{mg} / \mathrm{kg}$ body weight in a volume of $10 \mathrm{~mL} / \mathrm{kg}$ in $0.9 \%$ saline containing $5 \%$ DMSO and $1 \%$ tween 80 , whereas chicks of group 4 (standard group) were given an oral dose of chlorpromazine (antiemetic drugs) at the dose range of $150 \mathrm{mg} / \mathrm{kg}$ body weight. After $15 \mathrm{~min}$, copper sulfate was administered orally at $50 \mathrm{mg} / \mathrm{kg}$ body weight to chicks of all groups. Same process was repeated by using cispaltin $(10 \mathrm{mg} / \mathrm{kg}$; IV) and fresh juice of Brasica $(10 \mathrm{mg} / \mathrm{kg}$; oral), instead of copper sulfate while other protocols remain same as before, then number of retches (an emetic action without emitting gastric material) was counted for the next $15 \mathrm{~min}$. The percentage retching inhibition was calculated as:

Retching inhibition $(\%)=[(\mathrm{A}-\mathrm{B}) / \mathrm{A}] \times 100$

Where, A and B represents the frequency of retching in control and experimental groups respectively.

Statistics and data analysis: All data was expressed as mean \pm SEM of triplicate. $\mathrm{EC}_{50}$ values were given with 95\% confidence intervals and the logarithmic dose response curves of different treatments were then plotted using computer software "Graph pad Prism" version 6, (Graph Pad Software, San Diego, CA, USA). Concentration-response curves were analyzed by nonlinear regression sigmoidal response curve (variable slope). Unpaired Student $t$-test was used for assessment of the observations. $p<0.05$ and $p<0.005$ were believed to be statistically significant and most significant values respectively.

\section{Results}

Phytochemical screening of R. acetosa: Methanolic extract of R. acetosa (Ra.ME) was found to contain alkaloids, saponin, tannin, carbohydrates, soluble starch, anthraquinones and flavonoids, while coumarin was absent.
Acute toxicity of $R$. acetosa: Acute toxicity of methanolic extract of $R$. acetosa was tested at different doses $(2,4$ and $6 \mathrm{~g} / \mathrm{kg}$ ); there was no change in mice behavior and mortality up to the dose as high as $6 \mathrm{~g} / \mathrm{kg}$, indicating that the methanolic extract is safe up to the maximal tested dose and is higher than the normal therapeutic dose.

Spasmogenic and spasmolytic effect of $R$. acetosa on rabbit jejunum preparations: Methanolic extract of $R$. acetosa at the dose range of $0.01-1.0 \mathrm{mg} / \mathrm{mL}$ showed the spasmogenic effect on spontaneously contracting isolated rabbit jejunum preparations, which did not sustained and was subsequently followed by spasmolytic effect at the next higher dose $(3-10 \mathrm{mg} / \mathrm{mL})$ with $\mathrm{EC}_{50}$ value of $2.87 \mathrm{mg} / \mathrm{mL}(1.52-3.25,95 \% \mathrm{CI}: \mathrm{n}=3$ ) (Figure 1). The observed contractile responses to Ra.ME was expressed as percentage of the maximal response to acetylcholine $(0.3 \mu \mathrm{M})$, i.e., $12.57 \pm 1.7,20.26 \pm 0.76,25.30 \pm 1.7,31.3 \pm$ 1.2 , and $46.23 \pm 5.2$ (mean \pm SEM, $n=3$ ), at the concentration range of $0.01,0.03,0.1,0.3$, and $1.0 \mathrm{mg} / \mathrm{mL}$, respectively (Figure 2). In the presence of atropine $(0.1$ $\mu \mathrm{M})$, spasmogenic effect was abolished while the spasmolytic effect was observed with $\mathrm{EC}_{50}$ value of 1.57 $\mathrm{mg} / \mathrm{mL}(95 \% \mathrm{CI}: 1.12-1.95, \mathrm{n}=3)$ as shown in Figure 1.

When tested against $\mathrm{K}^{+}(80 \mathrm{mM})$-induced contractions, Ra.ME caused the dose dependent relaxation with $\mathrm{EC}_{50}$ value of $1.3 \mathrm{mg} / \mathrm{mL}$ (95\% CI: 0.92-1.75, $\mathrm{n}=3$ ), while verapamil, (positive control) inhibited the $\mathrm{K}^{+}(80 \mathrm{mM})$ induced contractions, with $\mathrm{EC}_{50}$ value of $0.15 \mathrm{mg} / \mathrm{mL}$ (95\% CI: 0.01-0.65, n=3) (Figure 3). Ra.ME shifted the $\mathrm{Ca}^{+2}$-concentration response curves at the dose range of

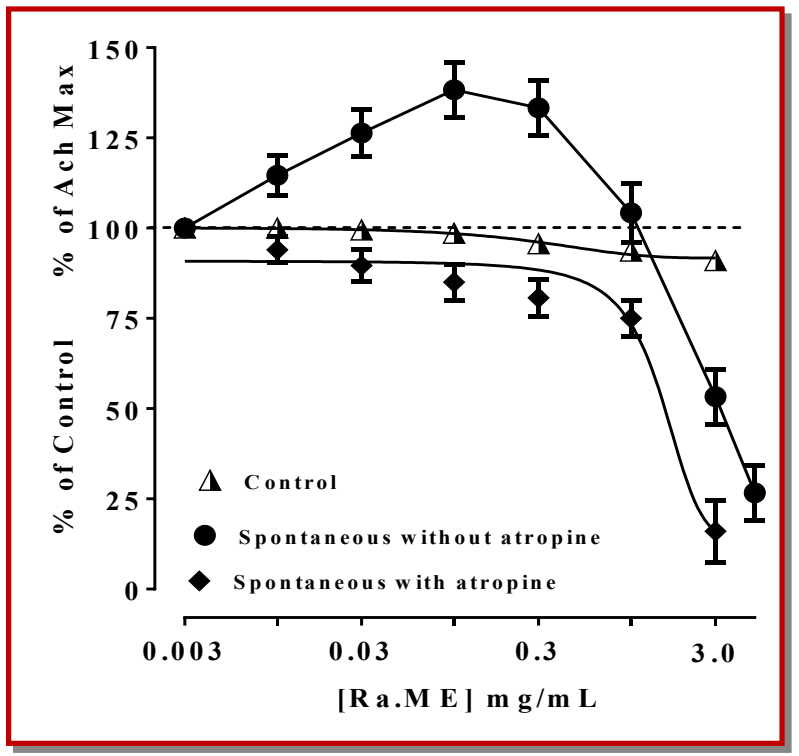

Figure 1: Concentration-response curves, showing the effect of Ra.ME in the absence and presence of atropine $(0.1 \mu \mathrm{M})$ on spontaneously contracting isolated rabbit jejunum. The spasmogenic responses are expressed as percent of acetylcholine maximum (Ach Max) (Data are mean \pm S.E.M, $n=3$ ) 


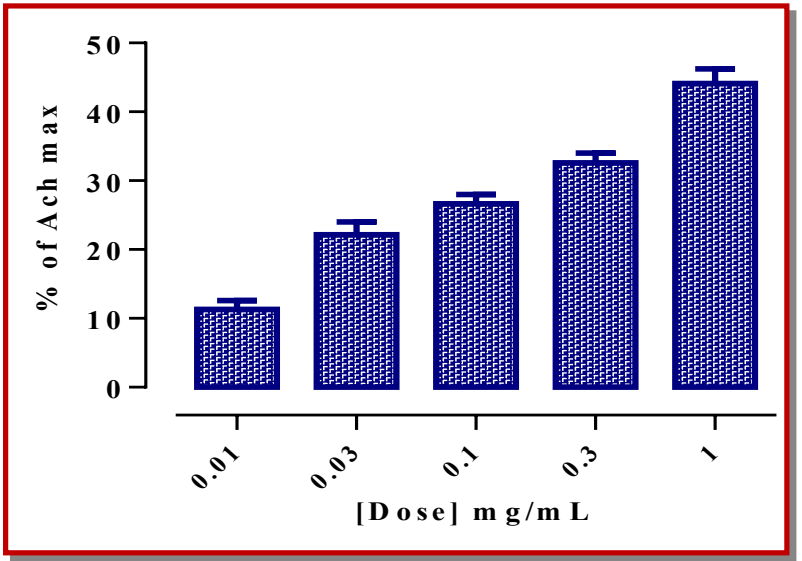

Figure 2: Bar diagram showing the effect of Ra.ME in comparison to the acetylcholine maximum response in isolated rabbit jejunum preparation (values are expressed as mean $\pm S E M, n=3$ )

(0.1-1.0 $\mathrm{mg} / \mathrm{mL}, \mathrm{n}=3)$ to the right, like that caused by verapamil at 0.03-0.3 $\mu \mathrm{M}(\mathrm{n}=3)$, as shown in Figure 4 .

Antiemetic potential of $R$. acetosa: In control groups, numbers of retches were $72 \pm 0.7,74 \pm 0.9$ and $75 \pm 0.6$ to whom normal saline $(10 \mathrm{~mL} / \mathrm{kg})$ was administered, followed by copper sulphate, Brasica compestris and cisplatin respectively. While in the experimental groups (50 mg/kg), number of retches were reduced with \% inhibition of emesis of 50.1, 46.0 and 25.5, whereas at the dose of $100 \mathrm{mg} / \mathrm{kg}$ number of retches were significantly reduced with \%inhibition of emesis of 75.5, 78.0 and 34.1 followed by copper sulphate, Brasica compestris and cisplatin respectively, which were comparable to standard drug chlorpromazine (Figure 5).

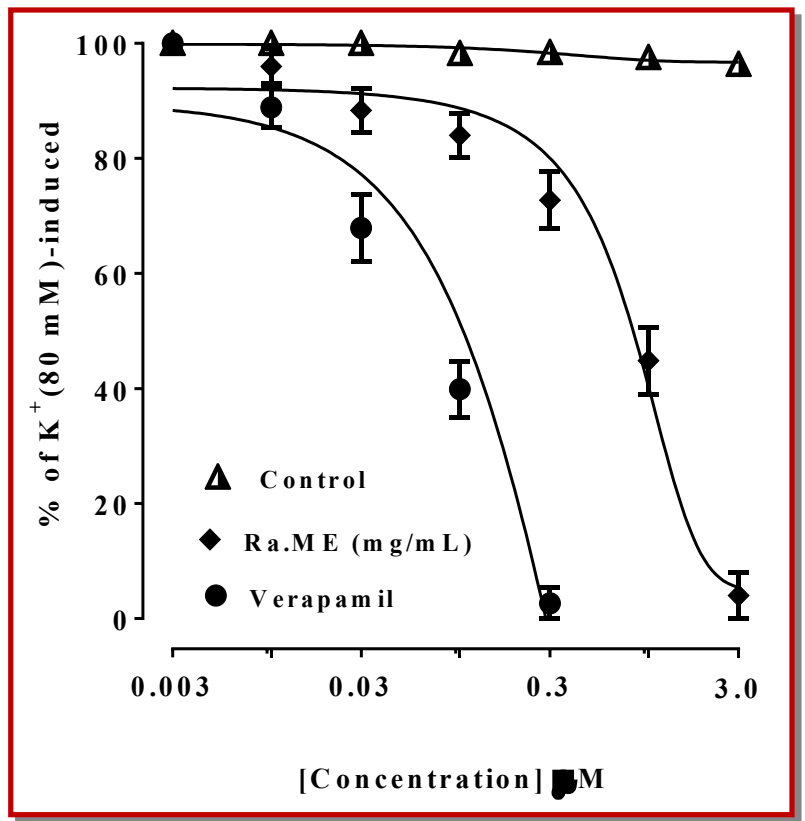

Figure 3: Concentration-dependent inhibitory effect of Ra.ME and verapamil against $\mathrm{K}^{+}(80 \mathrm{mM})$-induced contractions in isolated rabbit jejunum preparations (values are expressed as mean \pm SEM, $n=3$ )

\section{Discussion}

Methanolic extract of $R$. acetosa was tested for the presence of different phytoconstituents and it was found to contain alkaloids, saponin, tannin, carbohydrates, soluble starch, anthraquinones and flavonoids, while coumarins was absent. Oral dose of extract of $R$.

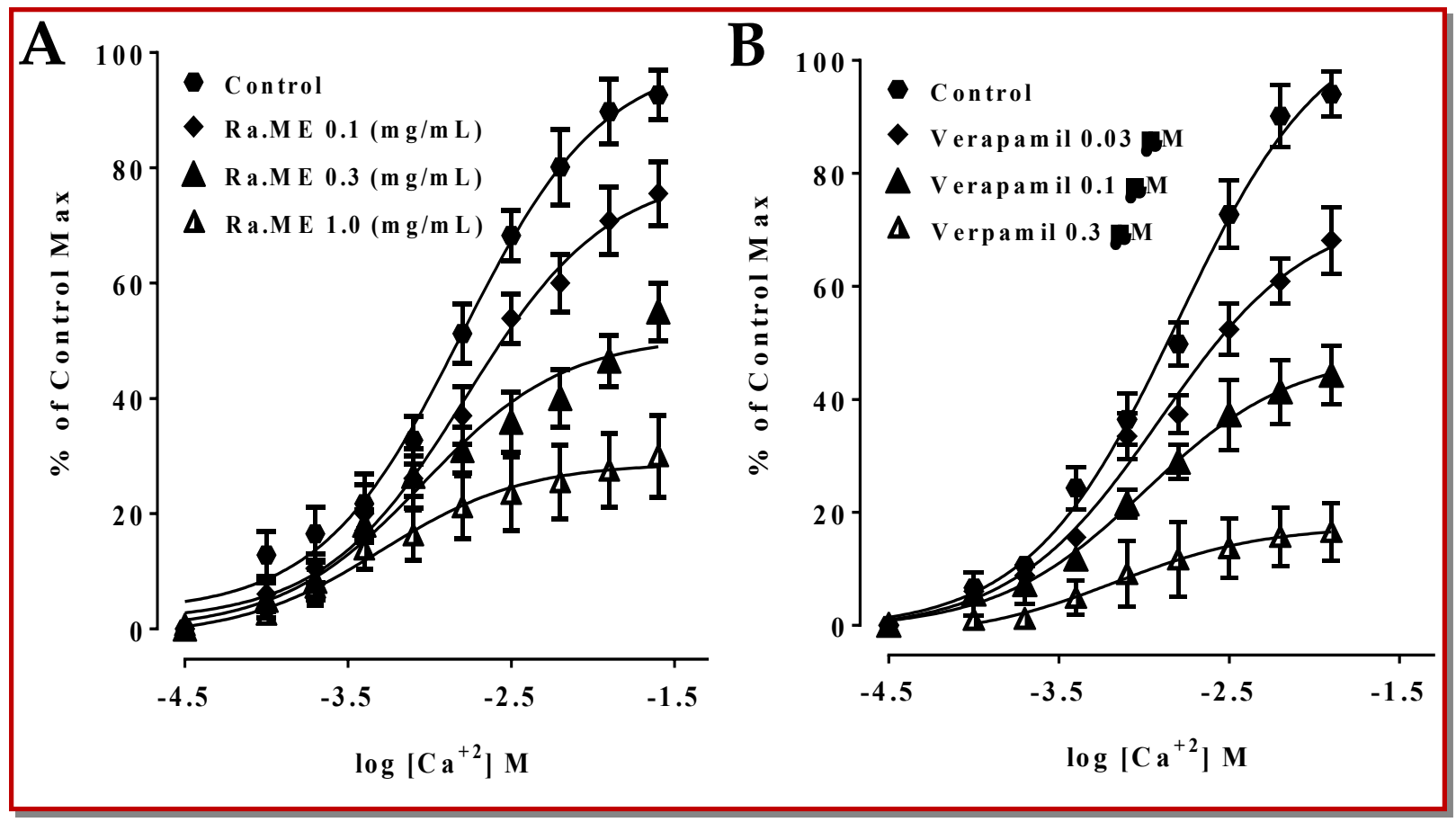

Figure 4: Concentration-response curves of $\mathrm{Ca}^{+2}$ in the absence and presence of different concentrations of (A) Ra.ME and (B) verapamil in isolated rabbit jejunum preparations (values are expressed as mean $\pm S E M, n=3$ ) 


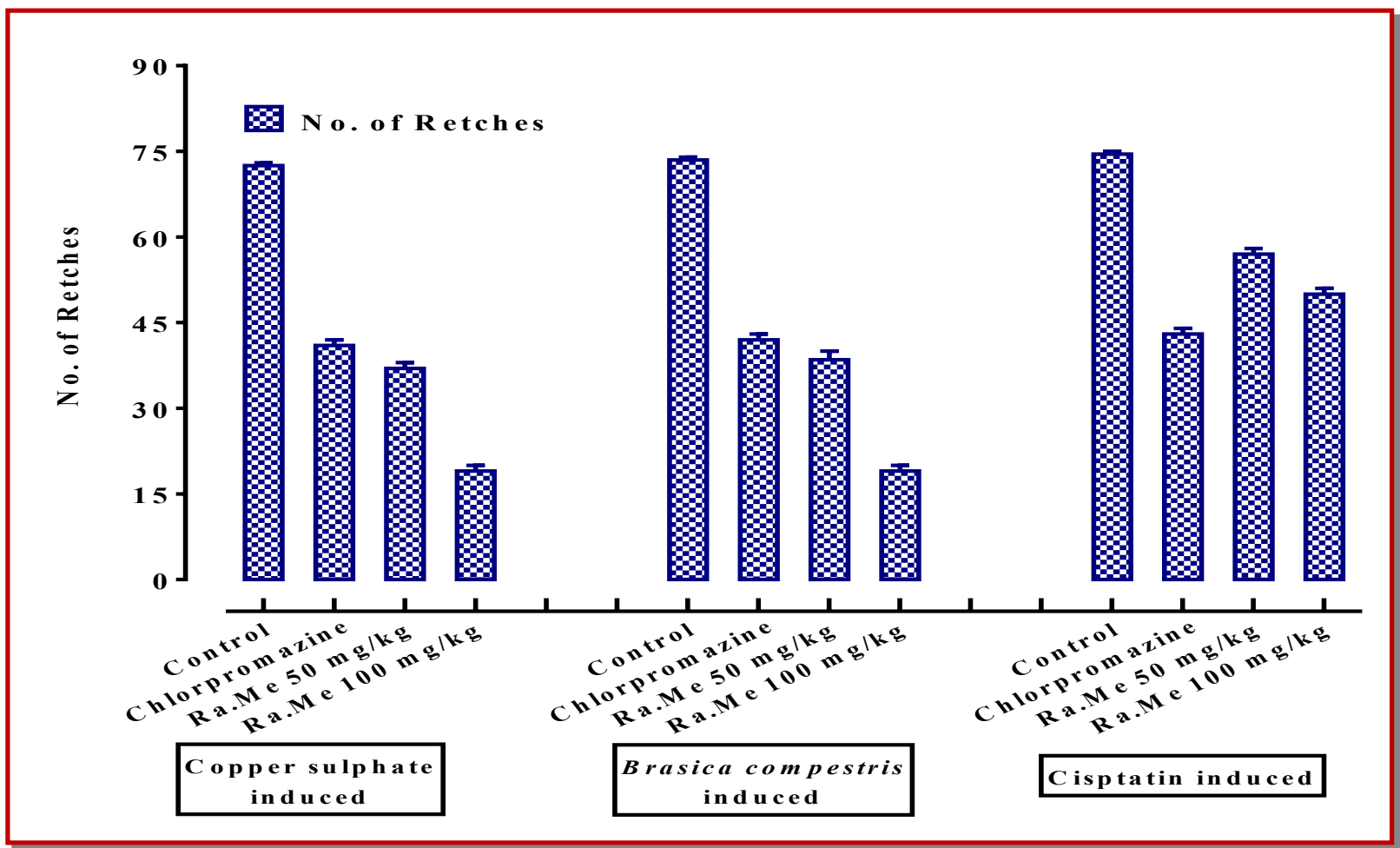

Figure 5: Antiemetic effect of Group 1: Control (normal saline); Group 2: standard drug (chlorpromazine); Group 3; R. acetosa (50 and $100 \mathrm{mg} / \mathrm{kg}$ ) against copper sulfate, Brasica compestris and cisplatin induced emesis in young chicks

acetosa as high as $6 \mathrm{~g} / \mathrm{kg}$, did not produced the lethality among the treated groups of mice.

Keeping in view of traditional uses of $R$. acetosa in gastrointestinal motility disorders, pharmacological study of methanolic extract was carried out on spontaneously contracting isolated rabbit jejunum preparations, to evaluate its possible effect, initially produced the spasmogenic effect (contractile effect), which is usually mediated through cholinergic mechanism as like by acetylcholine (Gilani et al., 2005; Hussain et al., 2014), so for the conformation of this mechanism, spontaneous contracting jejunum preparations were pretreated with muscarinic receptor antagonist (0.1 $\mu \mathrm{M}$ of atropine) (Delmendo et al., 1989), abolished the stimulatory effect of the methanolic extract, which indicates that the $R$. acetosa causes the gut stimulation via cholinergic pathway (Hussain et al., 2015a). Acetylcholine is a neurotransmitter released by the parasympathetic nervous system; regulate the peristaltic movement of the gut by acting on $M_{3}$ muscarinic receptor while atropine (antagonist) blocks muscarinic receptors (Brown and Taylor, 1996). The observed spasmogenic effect of $R$. acetosa validates its traditional use as anti-constipative agent in the hypomotility disorder of the gut. The spasmogenic effect was followed by the spasmolytic effect at next higher doses of the methanolic extract, indicating the co-existence of spasmogenic, and spasmolytic constituent(s), which is probably meant by the nature not to allow the spasmogenic effect going beyond the constipation, particularly at higher doses (Ghayur and Gilani , 2005).

It has been previously observed that spasmolytic effect of medicinal plants is usually mediated through $\mathrm{Ca}^{2+}$ channels blockade (Janbaz et al., 2012; Hussain et al., 2014). To elucidate whether the spasmolytic effect of $R$. acetosa is also mediated through the $\mathrm{Ca}^{2+}$ channels blockade, methanolic extract was tested on $\mathrm{K}^{+}(80 \mathrm{mM})$ induced contractions which is known to cause smooth muscles contractions through opening of the voltage dependent L-type $\mathrm{Ca}^{2+}$ channels, thus allowing the influx of extracellular $\mathrm{Ca}^{2+}$ causing a contractile effect (Bolton, 1979; Karaki et al., 1997), and substances inhibiting the $\mathrm{K}^{+}(80 \mathrm{mM})$-induced contraction are known as $\mathrm{Ca}^{2+}$ channels blockers, i.e. inhibitor of $\mathrm{Ca}^{2+}$ influx (Godfraind et al., 1986; Okumura et al., 1993). Methanolic extract, like verapamil (standard $\mathrm{Ca}^{+2}$ channel blocker), relaxed the $\mathrm{K}^{+}(80 \mathrm{mM})$-induced contractions, indicating the $\mathrm{Ca}^{2+}$ channels blocking action. The $\mathrm{Ca}^{2+}$ channels blocking effect of $R$. acetosa was further confirmed when it shifted the $\mathrm{Ca}^{2+}$ concentration response curves to the right, like that caused by verapamil, used as positive control.

The observed anti-cholinergic and $\mathrm{Ca}^{2+}$ antagonist effects of the $R$. acetosa might be due to presence of alkaloids and flavonoids, evident in preliminary phytochemical investigation, as these constituents have been reported to possess the anti-muscarinic (Broadley, 1996) and $\mathrm{Ca}^{2+}$ channel blocking (Revuelta et al., 1997) 
activities, respectively, while other mechanisms and constituents cannot be ruled out.

Based upon the traditional use of $R$. acetosa for the ailment of emesis, in vivo pharmacological study was carried out by adopting chick emetic model to evaluate its possible antiemetic effect. As emesis is caused by the activation of the vomiting centre located in medulla oblongata, directly by activation of motor pathway and/or indirectly following input from four principal areas, i.e., chemoreceptor trigger zone (CRTZ), GIT, cortex, thalamus, cerebral and vestibular region. The CRTZ is in the proximity to medulla and it is not protected by the blood brain barrier (Becker, 2010). On the basis of results it can be inferred that antiemetic response of $R$. acetosa $(100 \mathrm{mg} / \mathrm{kg}$ ) was more significant for the copper sulphate and Brasica compestris induced emesis which was comparable to chlorpromazine. So, it can be hypothesized that the antiemetic effect of $R$. acetosa can be likely mediated through inhibition of chemoreceptor trigger zone while exact mechanism is not clearly known.

\section{Conclusion}

This study shows the presence of cholinomimetic and calcium antagonistic constituents in the methanolic extract of $R$. acetosa. The cholinomimetic activity is likely to act as aperients (mild laxative) and provides the sound mechanistic back ground for the possible use of the plant in the traditional medicine for the constipation while the calcium antagonistic activity pharmacological rationale for its use in diarrhea, though additional mechanisms cannot be ruled out.

\section{References}

Akita Y, Yang Y, Kawai T, Kinoshita K, Koyama K, Takahashi K. New assay method for surveying anti-emetic compounds from natural sources. Nat Prod Res. 1998; 4: 72-77.

Arshad U, Janbaz KH, Bashir S, Rehman NU, Mehmood MH, Gilani AH. Ethnopharmacological studies on Chrozophora prostrata in perspective of its folkloric reputation as purgative. Bangladesh J Pharmacol. 2012; 7: 243-48.

Bae JY, Lee YS, Han SY, Jeong EJ, Lee MK, Kong JY, Ahn MJ. A comparison between water and ethanol extracts of Rumex acetosa for protective effects on gastric ulcers in mice. Biomol Ther. 2012; 20: 425.

Becker DE. Nausea, vomiting, and hiccups: A review of mechanisms and treatment. Anesth Prog. 2010; 57: 150-57.

Bicker J, Petereit F, Hensel A. Proanthocyanidins and a phloroglucinol derivative from Rumex acetosa L. Fitoterapia 2009; 80: 483-95.

Bolton TB. Mechanisms of action of transmitters and other substances on smooth muscle. Physiol Rev. 1979; 59: 606-718.
Broadley KJ. Autonomic Pharmacology. London, United Kingdom, Taylor and Francis, 1996.

Brown JH, Taylor P. Muscarinic receptor agonists and antagonists. In: The pharmacological basis of therapeutics. Gilman AG, Hardman JG, Limbird LE, Molinoff PB, Ruddon RW (eds). New York, McGraw-Hill, 1996, pp 141-59.

Delmendo RE, Michel AD, Whiting RL. Affinity of muscarinic receptor antagonists for three putative muscarinic receptor binding sites. Br J Pharmacol. 1989; 96: 457- 64.

Duke JA, Godwin MJB, duCellier J, Duke PK. Handbook of medicinal herbs. 2nd ed. New York, CRC Press, 2002, pp 683 -84 .

Eda M, Hayashi Y, Kinoshita K, Koyama K, Takahashi K, Akutu K. Anti-emetic principles of water extract of Brazilian Propolis. Pharm Biol. 2005; 43: 184-88.

Evans WC. Phytochemistry. In: Trease and Evans Pharmacognosy. 5th ed. Delhi, Elsevier, 2006, pp 135-50.

Farre AJ, Colombo M, Fort M, Gutierrez B. Differential effects of various $\mathrm{Ca}^{2+}$ antagonists. Gen Pharmacol. 1991; 2: 177-81.

Florczyk AP, Schuring JE, Brander WT. Cisplatin induced emesis in the ferret. A new animal model. Cancer Treat Resp. 1982; 66: 187-89.

Gescher K, Hensel A, Hafezi W, Derksen A, Kühn J. Oligomeric proanthocyanidins from Rumex acetosa L. inhibit the attachment of herpes simplex virus type-1. Antiviral Res. 2011; 89: 9-18.

Ghayur MN, Gilani AH. Pharmacological basis for the medicinal use of ginger in gastrointestinal disorders. Dig Dis Sci. 2005; 50: 1889-97.

Gilani AH, Bashir S, Janbaz KH, Shah AJ. Presence of cholinergic and calcium channel blocking activities explains the traditional use of Hibiscus rosasinensis in constipation and diarrhea. J Ethnopharmacol. 2005; 102: 289-94.

Gilani AH, Janbaz KH, Zaman M, Lateef A, Suri A, Ahmed HR. Possible presence of calcium channel blocker(s) in Rubia cordifolia: An indigenous medicinal plant. J Pakistan Med Assoc. 1994; 44: 82-85

Godfraind T, Miller R, Wibo M. Calcium antagonism and calcium entry blockade. Pharmacol Rev. 1986; 38: 321-26.

Hussain M, Bakhsh H, Aziz A, Majeed A, Khan IA, Mujeeb A, Farooq U. Comparative In vitro study of antimicrobial activities of flower and whole plant of Jasminum officinale against some human pathogenic microbes. J Pharm Alternative Med. 2013; 2: 33-43.

Hussain M, Raza S.M, Khan MRU, Majeed A. Assessment of antiemetic potential of crude extract of Vigna trilobata (Linn.) against different emetogenic stimuli: An in vivo study. Indo Am J Pharmaceut Res. 2015b; 5: 1588-93.

Hussain M, Raza SM, Janbaz KH. Pharmacological basis for the folkloric uses of Buxus wallichiana Baill. (Buxaceae) in gastrointestinal, respiratory and vascular disorders. Bangladesh J Pharmacol. 2015a; 10: 260-66.

Hussain M, Raza SM, Janbaz KH. Pharmacological evaluation and validation for the folkloric use of Oligochaeta ramose (Roxb.) in constipation and diarrhea. Bangladesh J Pharmacol. 2014; 9: 617-23. 
Janbaz KH, Haider S, Imran I, Zia-Ul-Haq M, De-Martino L, De-Feo V. Pharmacological evaluation of Prosopis cineraria (L.) Druce in gastrointestinal, respiratory, and vascular disorders. Evid Based Complement Alternat Med. 2012; 12: 1 $-7$.

Janbaz KH, Nisa M, Saqib F, Imran I, Zia-Ul-Haq M, Feo V.D. Bronchodilator, vasodilator and spasmolytic activities of methanolic extract of Myrtus communis L. J Physiol Pharmacol. 2013; 64: 479-84.

Janbaz KH, Shabbir A, Mehmood MH, Gilani AH. Pharmacological basis for the medicinal use of Rhus coriaria in hyperactive gut disorders. Bangladesh J Pharmacol. 2014; 9: 636-44.

Karaki H, Ozaki H, Hori M, Mitsui-Saito M, Amano K, Harada K, Miyamoto S, Nakazawa H, Won KJ, Sato K. Calcium movements, distribution, and functions in smooth muscle. Pharmacol Rev. 1997; 49: 157-230.

Kato T, Morita Y. C-glycosylfl avones with acetyl substitution from Rumex acetosa L. Chem Pharm Bull. 1990; 38: 2277.

Khare CP. Indian medicinal plants. An illustrated dictionary. New Delhi, India, Springer, 2007, p 562.

Kirtikar KR, Basu BD. Indian medicinal plants. Vol. 2. Dehradun, India, International Book Distributors, 1984.
Lee NJ, Choi JH, Koo BS, Ryu SY, Han YH, Lee SI, Lee DU. Antimutagenicity and cytotoxicity of the constituents from the aerial parts of Rumex acetosa. Biol Pharm Bull. 2005; 28: 2158-61.

Leonard BJ, Kennedy DA, Cheng FC, Chang KK, Seely D, Mills E. An in vivo analysis of the herbal compound essiac. Anticancer Res. 2006; 26: 3057-63.

Lim JP, Park YS, Hong MW, Kim DK. Quantitative analysis of anthraquinones from the roots of Korean Natural Rumex species plants. Kor J Pharmacogn. 2011; 42: 297-301.

National Research Council. Guide for the care and use of laboratory animals. Washington, DC, USA, National Academy Press, 1996.

Okumura K, Ichihara K, Nagasaka M, Oda N, Tajima K. Calcium entry blocking activities of MPC-1304 and of its enantiomers and metabolites. Eur J Pharmacol. 1993; 235: 6974 .

Revuelta MP, Cantabrana B, Hidalgo A. Depolarization-dependent effect of flavonoids in rat uterine smooth muscle contraction elicited by $\mathrm{CaCl}_{2}$. Gen Pharmacol-Vasc Syst. 1997; 29: 847-57.

Wegiera M, Kosikowska U, Malm A, Smolarz HD. Antimicrobial activity of the extracts from fruits of Rumex species. Cent Eur J Biol. 2011; 6: 1036-43. 